\title{
In vitro comparison of different mechanical prostheses suitable for replacement of the systemic atrioventricular valve in children
}

\author{
Tomaso Bottio, MD, PhD, Carlo Dal Lin, MD, Alban Lika, MD, Giulio Rizzoli, MD, Vincenzo Tarzia, MD, \\ Edward Buratto, MD, and Gino Gerosa, MD
}

Objective: The aim of the present study was to compare the hydrodynamics of 4 different mechanical prostheses fitting the atrioventricular annulus in children.

\begin{abstract}
Methods: We tested different inverted aortic prostheses with a prosthesis-annulus relationship in the mitral chamber of the Sheffield pulse duplicator (Department of Medical Physics and Clinical Engineering, Royal Hallamshire Hospital, Sheffield, UK), analyzed by comparing the prosthetic housing diameter and the predicted annulus diameter based on body surface area $\left(0.8\right.$ and $1 \mathrm{~m}^{2}$ corresponding to an annulus diameter of 18.8-20.2 mm). The On-X 19 (On-X Life Technologies, Inc, Austin, Tex), SJM Regent 19 (St Jude Medical Inc, St Paul, Minn), Sorin Overline 18 (Sorin Biomedica, Saluggia, Italy), and Medtronic Advantage Supra 19 (Medtronic Inc, Minneapolis, Minn) valves with a housing diameter of 19 to $20 \mathrm{~mm}$ were hydrodynamically compared. The tests were carried out at increasing pulse rate of 72 , 80,100 , and 120 beats/min for a stroke volume of 20 and $30 \mathrm{~mL}$. Therefore, cardiac output ranged from 1.44 to $3.6 \mathrm{~L} / \mathrm{min}$.
\end{abstract}

Results: Regardless of the pulse rate and stroke volume, the Medtronic Advantage Supra valve showed the highest mean diastolic pressure difference at each cardiac output $(P<.05)$. The mean gradients were significantly lower for the Sorin Overline valve regardless of the cardiac output, stroke volume, and pulse rate $(P<.05)$. The effective orifice areas observed followed exactly the same behavior: the lowest for the Medtronic Advantage Supra valve and the highest for the Sorin Overline valve. The Sorin Overline valve showed the highest closure volumes $(P<.05)$, and the On-X prosthesis showed the highest leakage volumes $(P<.05)$. The Sorin Overline valve had the highest total regurgitant volume $(P<.05)$, and the Medtronic Advantage Supra valve had the lowest total regurgitant volume $(P<.05)$. The On- $\mathrm{X}$ valve showed the highest total energy loss regardless of the pulse rate at $20 \mathrm{~mL}$ of stroke volume, which was comparable to the SJM Regent and Sorin Overline valves at increased stroke volume. The Medtronic Advantage Supra valve showed the lowest total energy loss regardless of cardiac outputs $(P<.05)$.

Conclusions: This hydrodynamic evaluation model allowed us to compare the efficiency of currently available valve prostheses suitable for atrioventricular replacement in children. Among these prostheses, the Sorin Overline valve showed the best diastolic performance. On the other hand, for total energy loss, the Medtronic Advantage Supra valve demonstrated excellent performance. (J Thorac Cardiovasc Surg 2012;143:558-68)

Repair of the mitral valve in children is the preferred surgical option, but dysplastic valves and complicated pathologies of the mitral apparatus may present technical difficulties, and valve replacement may be necessary.

Evaluation of the hydrodynamics of prosthetic valves is a useful indicator of expected clinical performance, but has the hypothetic differential hydraulic behavior between

\footnotetext{
From the Cardiovascular Institute, University of Padova, Italy.

Disclosures: Authors have nothing to disclose with regard to commercial support.

Received for publication March 5, 2010; revisions received April 28, 2011; accepted for publication May 18, 2011; available ahead of print Sept 5, 2011.

Address for reprints: Tomaso Bottio, MD, PhD, Cardiovascular Institute, University

of Padua, Via Giustiniani, 2, 35100 Padova, Italy (E-mail: tbottio@gmail.com).

0022-5223/\$36.00

Copyright (c) 2012 by The American Association for Thoracic Surgery

doi:10.1016/j.jtcvs.2011.05.033
}

different prosthetic mitral heart valves been sufficiently and comprehensively revealed?

All valve substitutes are responsible for some residual stenosis because of the design, size, material, and implantation technique used. This can be minimized by an accurate surgical strategy and preoperative prosthesis selection. ${ }^{1-5}$ To answer our question in this report, we analyzed the hydrodynamic performance of 4 bileaflet mechanical prostheses: On-X 19 (On-X Life Technologies, Inc, Austin, Tex), SJM Regent 19 (St Jude Medical Inc, St Paul, Minn), Sorin Overline 18 (Sorin Biomedica, Saluggia, Italy), and Medtronic Advantage Supra 19 (Medtronic Inc, Minneapolis, Minn). All prostheses, regardless of the manufacturer's nominal size, were fitted onto a 21-mm diameter valve holder of the Sheffield pulse duplicator (SPD; Department of Medical Physics 

Abbreviations and Acronyms
$\mathrm{CO}=$ cardiac output
$\mathrm{EOA}=$ effective orifice area
$\mathrm{LA}=$ left atrium
$\mathrm{MVR}=$ mitral valve replacement
$\mathrm{PR}=$ pulse rate
$\mathrm{SD}=$ standard deviation
SPD $=$ Sheffield pulse duplicator
$\mathrm{SV}=$ stroke volume
TEL $=$ total energy loss
$\mathrm{TRV}=$ total regurgitant volume
$\mathrm{VCV}=$ valve closing volume
$\mathrm{VLV}=$ valve leakage volume

and Clinical Engineering, Royal Hallamshire Hospital, Sheffield, UK).

\section{MATERIALS AND METHODS}

The SPD is a system designed to perform pulsatile hydrodynamic testing of prosthetic heart valves by means of continuous measurement of flow and transvalvular pressure gradients (Figure 1). The system has been described in detail. ${ }^{6-8}$ We tested different inverted aortic prostheses in the mitral chamber of the SPD with a prosthesis-annulus relationship analyzed by comparing the prosthetic housing diameter and the predicted annulus diameter based on the body surface area of the subjects. We considered a body surface area of 0.8 to $1 \mathrm{~m}^{2}$ corresponding to an annulus diameter of 18.8 to $20.2 \mathrm{~mm}$ in children. Three production quality samples of each model were tested. Each valve was tested 10 times at each different cardiac output (CO). This resulted in 40 tests for each valve and 120 tests for each valve model. The mean and standard deviation (SD) of each measurement parameter for each test condition was calculated from the 10 repeated tests on each valve. The sizes of the tested valves fitting an annulus diameter from 18.8 to 20.2 mm were as follows: On-X, 19; SJM Regent, 19; Sorin Overline, 18; and Medtronic Advantage Supra, 19. We considered the housing diameter as external diameter, and a larger label size of each prosthesis could not be accommodated in a 21-mm SPD holder. The prostheses were hydrodynamically compared. Thus, the valves were inserted into the pulse duplicator holder composed of 2 O-rings, and the prosthesis was secured between these rings. A supplied rubber washer was used to fill and seal the gap between the 2 parts of the mounting ring. Therefore, paravalvular leakage was not allowed in any test. Simultaneous pressure measurements were recorded by using electromagnetic flowmeters and pressure transducers located upstream and downstream of the mitral valve. Each valve was tested at a different stroke volume (SV) and pulse rate (PR) to assess the change in the prostheses' hydrodynamics during hypothetic somatic growth. The tests were carried out at increasing PR of $72,80,100$, and 120 beats/min for an SV of 20 and $30 \mathrm{~mL}$. CO varied between 1.44 and $3.6 \mathrm{~L} / \mathrm{min}$ (representative of $0.8-1.2 \mathrm{~m}^{2}$ body surface area and in the range of COs required by the Food and Drug Administration for in vitro tests). The aortic pressures were kept constant at 120/80 $\mathrm{mm} \mathrm{Hg}$. The system was filled with saline solution $(0.9 \%)$, as recommended by the manufacturer, to optimize measurements. ${ }^{9}$ Forward flow pressure decrease, closing volume, leakage volume, total regurgitant volume (TRV), and effective orifice area $(\mathrm{EOA}=$ [root mean square diastolic flow rate $\{$ milliliters/second $\} / 51.6 *$ square root mean diastolic pressure difference $\{$ millimeters mercury\}/1.0085]) were calculated as previously published by Walker and colleagues ${ }^{10}$ and according to the SPD Manual (Figure 2). All data were expressed as means \pm SD. The chi-square test was used for statistical comparison. The following parameters were determined for each cardiac cycle: mean gradient (millimeters mercury), EOA (square centimeters), performance index (EOA, square centimeters/external diameter, centimeters), TRV (milliliters), valve closing volume (VCV, milliliters), valve leakage volume (VLV, milliliters), and total energy loss (TEL, calculated by integrating the flow times the transvalvular pressure over relevant flow interval). A conversion factor of 0.1333 is applied to convert the energy from millimeters mercury to millijoule). All 7 mitral timing points considered by the SPD software are shown in Figure 2.

\section{RESULTS}

\section{Measurements for All Valve Models (Figure 3)}

Table 1 shows the measurements for all valve models by nominal size. The value is a mean measurement made with a highly professional ruler. Two different independent investigators measured all the prostheses. Measurements are the expression of a mean value of 3 different valves for each model, including the maximum and minimum values obtained for each valve.

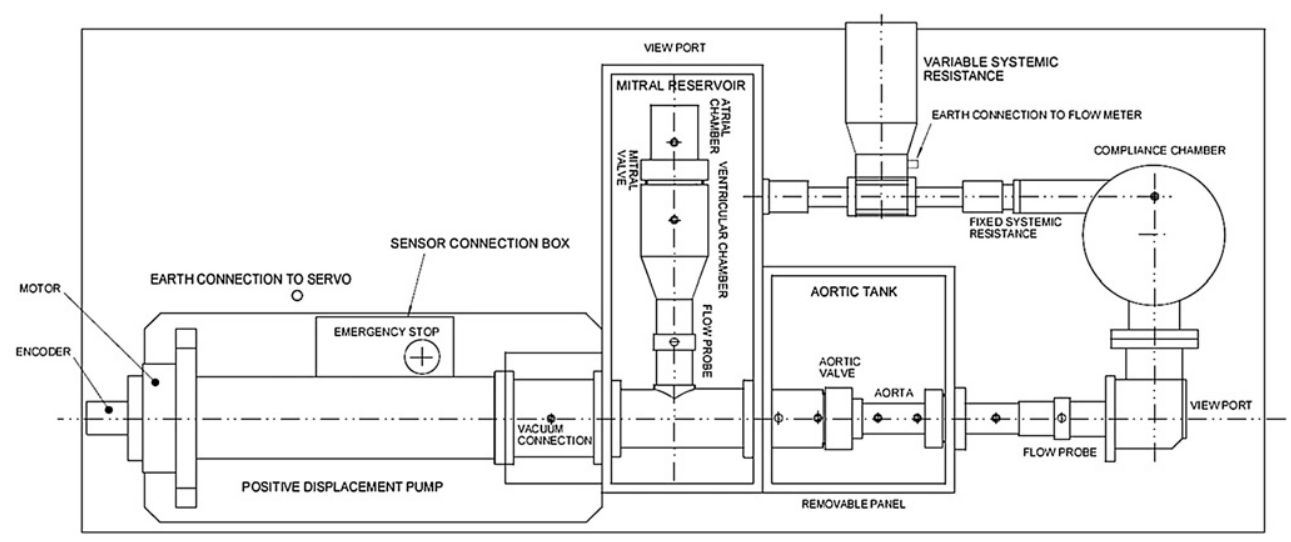

FIGURE 1. The SPD. (Reprinted with permission from the SPD Instructions Manual, page 5. ${ }^{9}$ ) 


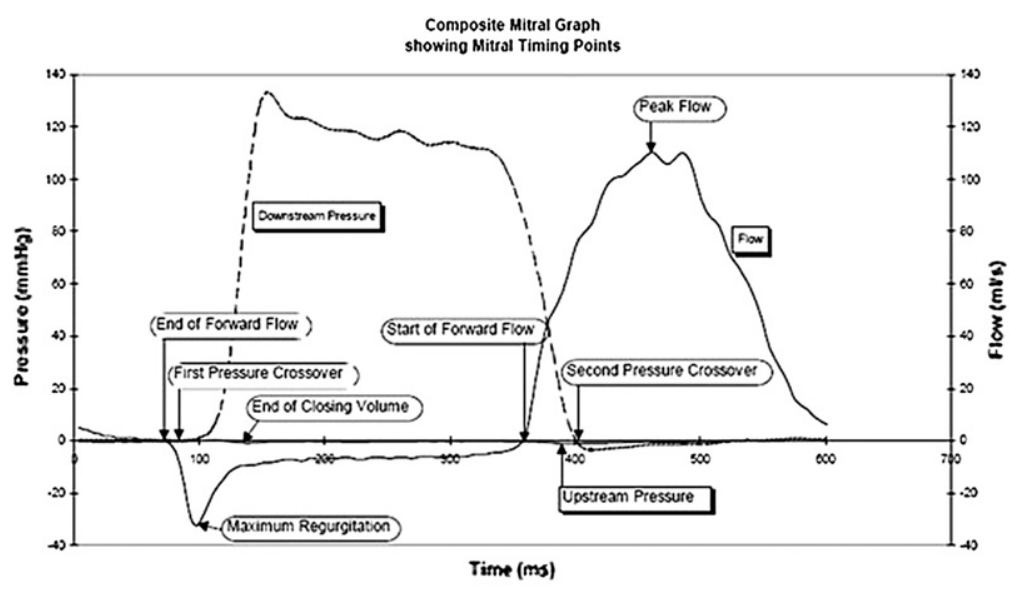

Mitral Parameters

The seven mitral timing points are defined as: The following mitral parameters are calculated. with timing points identified for the start and

\begin{tabular}{|c|c|c|}
\hline $\mathrm{MI}$ & First Pressure Crossover & $\begin{array}{l}\text { The point when dosnstream presstre first } \\
\text { exceeds upstream pressure but never carlier } \\
\text { than the end of fonvard fiow. }\end{array}$ \\
\hline$\overline{M 2}$ & End of Fonvasd Flow & $\begin{array}{l}\text { The point when a pegative thow signal is } \\
\text { identified. }\end{array}$ \\
\hline$\overline{M S 3}$ & M.aximum Regurgitation & The point of maximum negative thow: \\
\hline$\overline{M 4}$ & End of Closing Volume & $\begin{array}{l}\text { Defined for mitral tests as the point when a } \\
\text { tamgent to the rising edfec of the closing volume } \\
\text { noech would stoss the time axis. }\end{array}$ \\
\hline MS & Stant of Fervard Flosx & $\begin{array}{l}\text { The point when a positive thox signal is } \\
\text { identified. }\end{array}$ \\
\hline $\mathrm{M6}$ & Scsond Pressure Crossover & $\begin{array}{l}\text { The point when downstream pressure falls } \\
\text { below upstream pressure. }\end{array}$ \\
\hline M7 & Peak Diastolic Flow & The point of maximum positive thow: \\
\hline
\end{tabular}

\begin{tabular}{|c|c|c|c|}
\hline Paraineter & Start & End & Description \\
\hline Mean diastolic atrial pressure & M6 & $\mathrm{MI}$ & Mean upstream pressure (diastole) \\
\hline Mean diastolic ventricular pressure & M6 & MI & Mean downtream pressure (diasole) \\
\hline Mean diastolic pressure difference & M6 & MI & $\begin{array}{l}\begin{array}{l}\text { Mean } \\
\text { (diastole) }\end{array} \quad \text { (upstream-downstream) } \\
\end{array}$ \\
\hline 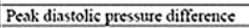 & M6 & MI & Single largest value \\
\hline Mean cyclical ventricular pressure & $\cdot$ & $\cdot$ & Mean dowmstream pressure (cycle) \\
\hline Pressure difference at peak flow & - & - & Value at timing point $M 7$ \\
\hline $\begin{array}{l}\text { Measured stroke volume (MSV) } \\
\text { (MS) }\end{array}$ & MS & M2 & \begin{tabular}{|l|} 
Measured by flowmeter \\
\end{tabular} \\
\hline Mean diastolic flowrate & M5 & $\mathrm{MI2}$ & Mean flow \\
\hline RMS diastolic flowrate & M5 & $\mathrm{M} / 2$ & RMS flow \\
\hline \begin{tabular}{|l} 
Maxinum instantancous flowrate \\
\end{tabular} & . & . & Single largest value \\
\hline \begin{tabular}{|l} 
Total regurgitant volume (TRV) \\
\end{tabular} & $\mathrm{M} / 2$ & M5 & Reverse flow during cycle \\
\hline Valve closing volume & M2 & $\mathrm{M} / 4$ & Volume associated with closture \\
\hline Valve leakage volume & $\mathrm{M} / 4$ & MI5 & Remainder \\
\hline Regursitant fraction & 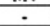 & - & TRV/MSV $\times 100 \%$ \\
\hline
\end{tabular}

FIGURE 2. Mitral timing points. (Reprinted with permission from the SPD Instructions Manual, page $35 .^{9}$ )

Internal orifice diameter. The largest internal orifice diameter was observed for the Sorin Overline valve, followed by the SJM Regent and On-X valve. However, when compared with the label size, the actual internal orifice diameter was inferior by $2.2 \mathrm{~mm}$ for the Medtronic Advantage Supra, by $1.6 \mathrm{~mm}$ for the On-X valve, and by $1.2 \mathrm{~mm}$ for the SJM Regent valve. Only the Sorin Overline valve had an internal diameter equal to the label size.

External orifice diameter. The largest external diameter was observed for the On-X valve $(20.1 \mathrm{~mm})$ followed by the Sorin Overline $(19.2 \mathrm{~mm})$, SJM Regent $(19 \mathrm{~mm})$, and Medtronic Advantage Supra (18.5 mm) valves.

Height. The On-X $(10.8 \mathrm{~mm})$ and SJM Regent $(9.07 \mathrm{~mm})$ are the tallest prostheses. The Sorin Overline $(6.6 \mathrm{~mm})$ and Medtronic Advantage Supra $(6 \mathrm{~mm})$ are the shortest prostheses.

\section{In Vitro Performances}

Stroke volume 20. The obtained mean values and SDs are expressed according to the $4 \mathrm{COs}$ adopted. The results are shown in Tables 2 to 5 and Figures 4 and 5 .

Mean gradients. The Medtronic Advantage Supra had the highest mean gradients compared with the other tested valves $(P<.05)$, showing a rapid increase from 0.41 to $1.03 \mathrm{~mm} \mathrm{Hg}$ when the PR increased from 80 to 120 beats/ min. The other prostheses showed significantly lower mean gradients $(P<.05)$. The On- $\mathrm{X}$ valve had mean gradient values comparable to the Medtronic Advantage Supra valve only at 72 and 80 beats $/ \mathrm{min}(P>.05)$. The Sorin Overline valve showed the lowest mean gradients when compared with the other tested valves $(P<.05)$.

Effective orifice area. The Sorin Overline valve showed the highest EOA regardless of $\mathrm{CO}(P<.05)$. The EOA

TABLE 1. Measurements made for all valve models by nominal size

\begin{tabular}{|c|c|c|c|c|}
\hline Model & Label size & External diameter $(\mathbf{m m})$ & Internal diameter $(\mathbf{m m})$ & Height (mm) \\
\hline On-X (On-X Life Technologies, Inc, Austin, Tex) & 19 & 20.1 & 17.4 & 10.8 \\
\hline SJM Regent (St Jude Medical Inc, St Paul, Minn) & 19 & 19 & 17.8 & 9.07 \\
\hline Sorin Overline (Sorin Biomedica, Saluggia, Italy) & 18 & 19.2 & 18 & 6.6 \\
\hline Medtronic ADV Supra (Medtronic Inc, Minneapolis, Minn) & 19 & 18.5 & 16.8 & 6 \\
\hline
\end{tabular}


TABLE 2. Medtronic Advantage Supra 19: Obtained mean values and standard deviations expressed according to each cardiac output adopted

\begin{tabular}{|c|c|c|c|c|c|c|}
\hline Model & $\begin{array}{c}\text { Cardiac output } \\
(\mathrm{L} / \mathrm{min})\end{array}$ & $\begin{array}{l}\text { Pulse rate } \\
\text { (beats/min) }\end{array}$ & $\begin{array}{c}\text { Stroke } \\
\text { volume }(\mathbf{m L}) \\
\end{array}$ & $\begin{array}{c}\text { Mean diastolic pressure } \\
\text { difference }(\mathrm{mm} \mathrm{Hg})\end{array}$ & $\begin{array}{c}\text { Total regurgitant } \\
\text { volume }(\mathrm{mL})\end{array}$ & $\begin{array}{l}\text { Valve closing } \\
\text { volume }(\mathrm{mL}) \\
\end{array}$ \\
\hline \multirow[t]{8}{*}{ Medtronic Advantage Supra 19} & 1.44 & 72 & 20 & $0.41 \pm 0.02$ & $2.02 \pm 0.13$ & $1.32 \pm 0.24$ \\
\hline & 2.16 & 72 & 30 & $0.94 \pm 0.03$ & $1.52 \pm 0.12$ & $1.07 \pm 0.17$ \\
\hline & 1.60 & 80 & 20 & $0.42 \pm 0.02$ & $2.45 \pm 0.16$ & $1.50 \pm 0.18$ \\
\hline & 2.40 & 80 & 30 & $1.05 \pm 0.03$ & $2.1 \pm 0.17$ & $1.18 \pm 0.20$ \\
\hline & 2.00 & 100 & 20 & $0.69 \pm 0.02$ & $2.25 \pm 0.19$ & $1.46 \pm 0.15$ \\
\hline & 3.00 & 100 & 30 & $1.69 \pm 0.03$ & $1.83 \pm 0.15$ & $1.09 \pm 0.15$ \\
\hline & 2.40 & 120 & 20 & $1.03 \pm 0.02$ & $1.92 \pm 0.15$ & $1.31 \pm 0.18$ \\
\hline & 3.60 & 120 & 30 & $2.47 \pm 0.05$ & $1.51 \pm 0.14$ & $0.96 \pm 0.14$ \\
\hline
\end{tabular}

observed with the Medtronic Advantage Supra valve at 72 and 80 beats/min was comparable to those observed with the On-X valve $(P>.05)$ but significantly diverged at increasing PRs.

Total regurgitant volume. The Sorin Overline and On-X valves showed the highest TRV for lower COs, becoming significantly higher when PRs increased from 100 to 120 beats/min $(P<.05)$. The Medtronic Advantage Supra valve showed the lowest TRV, which was smaller for each $\mathrm{CO}$ when compared with those obtained with the other tested valves $(P<.05)$. The SJM Regent valve showed intermediate TRVs that were comparable to the values obtained with the On-X valve at PRs of 100 and 120 beats/min $(P>.05)$.

Valve closing volume. The Sorin Overline valve showed the highest VCV at each $\mathrm{CO}$ in comparison with the other tested valves $(P<.05)$. The performances of the other 3 valves were statistically different. The Medtronic Advantage Supra had low values of VCV at each CO and a rather stable hemodynamic behavior for increased COs.

Valve leakage volume. The On-X valve showed the highest VLV at each CO, showing decreasing values for PRs ranging from 100 to 120 beats/min $(P<.05)$. Both the SJM Regent and Sorin Overline valves showed intermediate values, being comparable at 72 and 80 beats/min PRs $(P>$ $.05)$ and becoming significantly different at increasing PRs $(P<.05)$. The Medtronic Advantage Supra valve showed the lowest VLV, which was significantly lower at each $\mathrm{CO}$, when compared with that obtained with the other valves $(P<.05)$.

Total energy loss. The On- $\mathrm{X}$ valve showed the highest TEL at 72,80 , and 100 beats/min of PR $(P<.05)$, showing decreasing values at the highest PR $(P>.05)$. The Sorin Overline valve showed the highest TEL at 120 beats/min of PR $(P<.05)$. The Medtronic Advantage Supra valve showed the lowest TEL, which was significantly lower at each $\mathrm{CO}$, when compared with that obtained with the other valves $(P<.05)$.

\section{Stroke Volume 30}

The obtained mean values and SDs are expressed according to the 4 COs adopted, and the results are shown in Tables 2 to 5 and Figures 4 and 5 .

Mean gradients. The Medtronic Advantage Supra showed the highest mean gradients in comparison with other tested

TABLE 3. St Jude Reagent 19: Obtained mean values and standard deviations expressed according to each cardiac output adopted

\begin{tabular}{|c|c|c|c|c|c|c|}
\hline Model & $\begin{array}{c}\text { Cardiac output } \\
(\mathrm{L} / \mathrm{min})\end{array}$ & $\begin{array}{c}\text { Pulse rate } \\
\text { (beats/min) }\end{array}$ & $\begin{array}{c}\text { Stroke } \\
\text { volume }(\mathbf{m L}) \\
\end{array}$ & $\begin{array}{c}\text { Mean diastolic pressure } \\
\text { difference }(\mathbf{m m ~ H g})\end{array}$ & $\begin{array}{c}\text { Total regurgitant } \\
\text { volume }(\mathrm{mL})\end{array}$ & $\begin{array}{l}\text { Valve closing } \\
\text { volume }(\mathbf{m L}) \\
\end{array}$ \\
\hline \multirow[t]{8}{*}{ St Jude Reagent 19} & 1.44 & 72 & 20 & $0.14 \pm 0.01$ & $3.00 \pm 0.12$ & $1.80 \pm 0.18$ \\
\hline & 2.16 & 72 & 30 & $0.52 \pm 0.02$ & $3.98 \pm 0.11$ & $2.25 \pm 0.29$ \\
\hline & 1.60 & 80 & 20 & $0.27 \pm 0.01$ & $3.49 \pm 0.18$ & $1.90 \pm 0.21$ \\
\hline & 2.40 & 80 & 30 & $0.60 \pm 0.02$ & $4.15 \pm 0.15$ & $2.26 \pm 0.19$ \\
\hline & 2.00 & 100 & 20 & $0.43 \pm 0.02$ & $3.57 \pm 0.14$ & $2.13 \pm 0.23$ \\
\hline & 3.00 & 100 & 30 & $0.97 \pm 0.02$ & $3.42 \pm 0.14$ & $1.95 \pm 0.21$ \\
\hline & 2.40 & 120 & 20 & $0.65 \pm 0.01$ & $3.19 \pm 0.13$ & $1.95 \pm 0.20$ \\
\hline & 3.60 & 120 & 30 & $1.39 \pm 0.02$ & $3.37 \pm 0.18$ & $2.01 \pm 0.21$ \\
\hline
\end{tabular}




\begin{tabular}{|c|c|c|c|c|c|c|c|}
\hline \multirow[b]{2}{*}{$\begin{array}{l}\text { Valve leakage } \\
\text { volume (mL) }\end{array}$} & \multirow[b]{2}{*}{$\operatorname{EOA}\left(\mathrm{cm}^{2}\right)$} & \multirow[b]{2}{*}{$\begin{array}{c}\text { Performance } \\
\text { index }\left(\mathrm{cm}^{2} / \mathrm{cm}^{2}\right)\end{array}$} & \multicolumn{2}{|c|}{ Total energy loss } & \multirow[b]{2}{*}{$\begin{array}{c}\text { Forward flow } \\
\text { energy loss }(\mathbf{m} \mathbf{J})\end{array}$} & \multirow[b]{2}{*}{$\begin{array}{c}\text { Closing energy } \\
\text { loss }(\mathbf{J})\end{array}$} & \multirow[b]{2}{*}{$\begin{array}{c}\text { Leakage energy } \\
\text { loss (mJ) }\end{array}$} \\
\hline & & & $(\mathbf{m J})$ & $(\%)$ & & & \\
\hline $0.70 \pm 0.18$ & $1.31 \pm 0.18$ & 0.47 & 16.78 & 7.28 & 1.12 & 7.23 & 8.43 \\
\hline $0.45 \pm 0.15$ & $1.31 \pm 0.17$ & 0.47 & 18.34 & 4.96 & 4.99 & 7.48 & 5.88 \\
\hline $0.95 \pm 0.11$ & $1.33 \pm 0.14$ & 0.48 & 22.03 & 9.85 & 1.08 & 9.18 & 11.8 \\
\hline $0.92 \pm 0.14$ & $1.31 \pm 0.10$ & 0.47 & 26.56 & 7.08 & 5.55 & 9.04 & 11.9 \\
\hline $0.79 \pm 0.12$ & $1.32 \pm 0.15$ & 0.48 & 22.45 & 9.39 & 1.67 & 11.1 & 9.68 \\
\hline $0.74 \pm 0.12$ & $1.30 \pm 0.16$ & 0.47 & 28.74 & 6.98 & 8.04 & 10.9 & 9.85 \\
\hline $0.61 \pm 0.10$ & $1.30 \pm 0.16$ & 0.47 & 22.09 & 9.01 & 2.18 & 12.3 & 7.58 \\
\hline $0.55 \pm 0.13$ & $1.28 \pm 0.13$ & 0.46 & 29.83 & 6.83 & 11.0 & 11.3 & 7.52 \\
\hline
\end{tabular}

valves $(P<.05)$, showing a rapid increase from 1.05 to 2.47 $\mathrm{mm} \mathrm{Hg}$ when the PR increased from 80 to 120 beats/min, reflecting the same previous behavior. The other prostheses showed significantly lower mean gradients $(P<.05)$. The Sorin Overline valve showed the lowest mean gradients when compared with the other tested valves $(P<.05)$.

Effective orifice area. The Sorin Overline showed the highest EOA regardless of $\mathrm{CO}(P<.05)$. The SJM Regent, Medtronic Advantage Supra, and On- $X$ valves showed stable EOAs at increasing COs. The EOA observed with the Medtronic Advantage Supra remained the lowest of the group $(P<.05)$.

Total regurgitant volume. As observed in the $20 \mathrm{~mL} \mathrm{SV}$ test conditions, the Sorin Overline valve showed the highest TRV for each CO. Furthermore, the SJM Regent valve showed slightly lower values, becoming comparable to those observed with the Sorin Overline valve at maximal CO $(P>.05)$. The Medtronic Advantage Supra showed the lowest TRV, which was smaller for each $\mathrm{CO}$ when compared with those obtained with the other tested valves $(P<.05)$.

Valve closing volume. The Sorin Overline valve showed the highest VCV at each $\mathrm{CO}$ in comparison with the other tested valves $(P<.05)$. As observed in the previous test conditions, the performances of the other 3 valves were statistically different. The Medtronic Advantage Supra showed the lowest values of VCV at 72 and 120 beats/min of PRs $(P<.05)$ and values comparable to those observed with the On-X valve at intermediate COs $(P>.05)$.

Valve leakage volume. The On- $X$ Valve showed the highest VLV at each $\mathrm{CO}$, with decreasing values at increasing PR $(P<.05)$. Both the SJM Regent and Sorin Overline valves showed intermediate values, being comparable only at 72 beats/min PR $(P>.05)$ and significantly lower for the Sorin Overline at increasing PR $(P<.05)$. The Medtronic Advantage Supra valve showed the lowest VLV, which was significantly lower at each $\mathrm{CO}$, when compared with that obtained with the other valves $(P<.05)$, as observed in the previous test conditions.

Total energy loss. The On-X Valve showed the highest TEL at 72,80 , and 100 beats/min of PR, showing decreasing values at increasing PRs $(P<.05)$. The Sorin Overline valve showed the highest TEL at the maximal CO $(P<.05)$, being comparable to that observed with the On$\mathrm{X}$ valve at 100 beats/min of PR. The Medtronic Advantage Supra valve showed the lowest TEL, which was

TABLE 3. Continued

\begin{tabular}{|c|c|c|c|c|c|c|c|}
\hline \multirow{2}{*}{$\begin{array}{l}\text { Valve leakage } \\
\text { volume (mL) }\end{array}$} & \multirow[b]{2}{*}{ EOA $\left(\mathrm{cm}^{2}\right)$} & \multirow{2}{*}{$\begin{array}{c}\text { Performance } \\
\text { index }\left(\mathrm{cm}^{2} / \mathrm{cm}^{2}\right)\end{array}$} & \multicolumn{2}{|c|}{ Total energy loss } & \multirow{2}{*}{$\begin{array}{c}\text { Forward flow } \\
\text { energy loss }(\mathbf{m J})\end{array}$} & \multirow{2}{*}{$\begin{array}{c}\text { Closing energy } \\
\text { loss }(\mathbf{J})\end{array}$} & \multirow{2}{*}{$\begin{array}{c}\text { Leakage energy } \\
\text { loss (mJ) }\end{array}$} \\
\hline & & & $(\mathbf{m} \mathbf{J})$ & $(\%)$ & & & \\
\hline $1.20 \pm 0.11$ & $2.15 \pm 0.19$ & 0.76 & 25.35 & 11.1 & 0.33 & 10.4 & 14.7 \\
\hline $1.73 \pm 0.16$ & $1.73 \pm 0.16$ & 0.61 & 39.70 & 10.9 & 2.59 & 15.6 & 21.3 \\
\hline $1.59 \pm 0.10$ & $1.70 \pm 0.18$ & 0.60 & 31.04 & 13.9 & 0.55 & 11.8 & 18.7 \\
\hline $1.89 \pm 0.17$ & $1.72 \pm 0.13$ & 0.60 & 43.47 & 11.8 & 2.69 & 16.8 & 24.0 \\
\hline $1.44 \pm 0.10$ & $1.72 \pm 0.12$ & 0.60 & 33.78 & 14.7 & 0.75 & 15.8 & 17.2 \\
\hline $1.47 \pm 0.15$ & $1.62 \pm 0.15$ & 0.57 & 40.86 & 10.4 & 4.15 & 17.8 & 18.9 \\
\hline $1.24 \pm 0.09$ & $1.60 \pm 0.18$ & 0.56 & 32.93 & 13.7 & 1.10 & 17.1 & 14.7 \\
\hline $1.36 \pm 0.17$ & $1.71 \pm 0.19$ & 0.60 & 45.75 & 10.8 & 4.89 & 22.8 & 18.0 \\
\hline
\end{tabular}


TABLE 4. On-X 19: Obtained mean values and standard deviations expressed according to each cardiac output adopted

\begin{tabular}{|c|c|c|c|c|c|c|}
\hline Model & $\begin{array}{c}\text { Cardiac output } \\
(\mathrm{L} / \mathrm{min}) \\
\end{array}$ & $\begin{array}{c}\text { Pulse rate } \\
\text { (beats/min) }\end{array}$ & $\begin{array}{c}\text { Stroke } \\
\text { volume }(\mathbf{m L}) \\
\end{array}$ & $\begin{array}{c}\text { Mean diastolic pressure } \\
\text { difference }(\mathbf{m m ~ H g})\end{array}$ & $\begin{array}{c}\text { Total regurgitant } \\
\text { volume }(\mathbf{m L})\end{array}$ & $\begin{array}{l}\text { Valve closing } \\
\text { volume }(\mathbf{m L}) \\
\end{array}$ \\
\hline \multirow[t]{8}{*}{ On-X 19} & 1.44 & 72 & 20 & $0.38 \pm 0.02$ & $4.44 \pm 0.14$ & $2.21 \pm 0.28$ \\
\hline & 2.16 & 72 & 30 & $0.79 \pm 0.03$ & $4.09 \pm 0.13$ & $1.51 \pm 0.32$ \\
\hline & 1.60 & 80 & 20 & $0.39 \pm 0.04$ & $4.57 \pm 0.17$ & $2.14 \pm 0.35$ \\
\hline & 2.40 & 80 & 30 & $0.79 \pm 0.02$ & $3.04 \pm 0.18$ & $1.32 \pm 0.29$ \\
\hline & 2.00 & 100 & 20 & $0.59 \pm 0.02$ & $3.59 \pm 0.19$ & $1.84 \pm 0.34$ \\
\hline & 3.00 & 100 & 30 & $1.45 \pm 0.05$ & $2.95 \pm 0.12$ & $1.19 \pm 0.16$ \\
\hline & 2.40 & 120 & 20 & $0.88 \pm 0.04$ & $3.06 \pm 0.11$ & $1.75 \pm 0.31$ \\
\hline & 3.60 & 120 & 30 & $1.96 \pm 0.07$ & $2.61 \pm 0.10$ & $1.17 \pm 0.25$ \\
\hline
\end{tabular}

significantly lower at each $\mathrm{CO}$, when compared with that obtained with the other valves $(P<.05)$.

\section{DISCUSSION}

The evaluation of the hydrodynamics of prosthetic valves is a useful indicator of expected clinical performance. The aim of our study was to analyze the hydrodynamic performance of mechanical prostheses suitable for mitral valve replacement (MVR) in children by comparing their in vitro results regardless of label size.

MVR in infants and young children is an uncommon operation that historically has carried a higher mortality and worse long-term outcome than MVR in older children (10-12 years). ${ }^{11,12}$ The clinical course of children aged less than 5 years who undergo MVR is largely unknown, and these patients often require a second or third MVR. Raghuveer and colleagues ${ }^{13}$ recently reported that prosthesis survival can be predicted on the basis of age at first MVR and prosthesis size, dividing the pediatric patients aged less than 5 years into 3 risk groups. The risk is highest in patients aged less than 2 years, receiving prostheses less than $20 \mathrm{~mm}$ at first MVR. The medium-risk group is identified as patients aged less than 2 years and prosthesis size $20 \mathrm{~mm}$ or greater at first MVR or aged more than
2 years and prosthesis size less than $20 \mathrm{~mm}$ at first MVR. The low-risk group is identified as patients aged more than 2 years and prosthesis size $20 \mathrm{~mm}$ or greater at first MVR. The somatic growth is comparable regardless of the need for a second MVR, and there is an increment in prosthesis size at second MVR, suggesting continued annular growth, despite being fixed to the sewing ring. ${ }^{13}$ However, the discrepancy between prosthesis size and body weight is a predictor of outcome. Larger discrepancies are associated with higher early mortality. In addition, all valve substitutes are responsible for some residual stenosis because of design, size, material, and implantation technique used. Obviously, this could be minimized by an exacting surgical strategy and preoperative prosthesis selection. $^{1-8}$

In vivo echocardiographic analysis is useful because we can calculate hemodynamic prosthetic performance by observing mean transvalvular gradient and continuity equation valve area (EOA).

Transvalvular gradient is dependent on flow and EOA, and the EOA is clearly related to the internal diameter of the prosthesis. ${ }^{5}$ Investigators have suggested the use of a fixed value of in vivo measured EOA for comparison. ${ }^{5,14,15}$ However, the echocardiographic EOA has

TABLE 5. Sorin Overline 19: Obtained mean values and standard deviations expressed according to each cardiac output adopted

\begin{tabular}{|c|c|c|c|c|c|c|}
\hline Model & $\begin{array}{c}\text { Cardiac output } \\
(\mathrm{L} / \mathrm{min})\end{array}$ & $\begin{array}{c}\text { Pulse rate } \\
\text { (beats/min) }\end{array}$ & $\begin{array}{c}\text { Stroke } \\
\text { volume }(\mathbf{m L}) \\
\end{array}$ & $\begin{array}{c}\text { Mean diastolic pressure } \\
\text { difference }(\mathrm{mm} \mathbf{H g})\end{array}$ & $\begin{array}{c}\text { Total regurgitant } \\
\text { volume }(\mathrm{mL})\end{array}$ & $\begin{array}{l}\text { Valve closing } \\
\text { volume }(\mathrm{mL}) \\
\end{array}$ \\
\hline \multirow[t]{8}{*}{ Overline 18} & 1.44 & 72 & 20 & $0.07 \pm 0.01$ & $4.45 \pm 0.19$ & $2.96 \pm 0.11$ \\
\hline & 2.16 & 72 & 30 & $0.25 \pm 0.01$ & $4.54 \pm 0.15$ & $2.89 \pm 0.07$ \\
\hline & 1.60 & 80 & 20 & $0.03 \pm 0.01$ & $4.21 \pm 0.13$ & $2.96 \pm 0.11$ \\
\hline & 2.40 & 80 & 30 & $0.38 \pm 0.01$ & $4.19 \pm 0.15$ & $2.76 \pm 0.09$ \\
\hline & 2.00 & 100 & 20 & $0.14 \pm 0.01$ & $3.83 \pm 0.18$ & $2.76 \pm 0.09$ \\
\hline & 3.00 & 100 & 30 & $0.75 \pm 0.02$ & $3.72 \pm 0.13$ & $2.69 \pm 0.10$ \\
\hline & 2.40 & 120 & 20 & $0.32 \pm 0.02$ & $3.32 \pm 0.12$ & $2.77 \pm 0.06$ \\
\hline & 3.60 & 120 & 30 & $1.15 \pm 0.03$ & $3.29 \pm 0.16$ & $2.53 \pm 0.14$ \\
\hline
\end{tabular}


TABLE 4. Continued

\begin{tabular}{|c|c|c|c|c|c|c|c|}
\hline \multirow[b]{2}{*}{$\begin{array}{l}\text { Valve leakage } \\
\text { volume }(\mathrm{mL})\end{array}$} & \multirow[b]{2}{*}{$\operatorname{EOA}\left(\mathrm{cm}^{2}\right)$} & \multirow[b]{2}{*}{$\begin{array}{c}\text { Performance } \\
\text { index }\left(\mathrm{cm}^{2} / \mathrm{cm}^{2}\right)\end{array}$} & \multicolumn{2}{|c|}{ Total energy loss } & \multirow[b]{2}{*}{$\begin{array}{c}\text { Forward flow energy } \\
\text { loss }(\mathbf{m J})\end{array}$} & \multirow[b]{2}{*}{$\begin{array}{l}\text { Closing energy } \\
\text { loss }(\mathrm{J}) \\
\end{array}$} & \multirow[b]{2}{*}{$\begin{array}{c}\text { Leakage energ. } \\
\text { loss }(\mathbf{m} \mathbf{J})\end{array}$} \\
\hline & & & $(\mathbf{m J})$ & $(\%)$ & & & \\
\hline $2.23 \pm 0.47$ & $1.32 \pm 0.18$ & 0.42 & 41.34 & 19.0 & 1.13 & 14.1 & 26.1 \\
\hline $2.58 \pm 0.46$ & $1.40 \pm 0.19$ & 0.44 & 48.68 & 12.8 & 4.49 & 11.6 & 32.6 \\
\hline $2.43 \pm 0.51$ & $1.40 \pm 0.15$ & 0.44 & 45.52 & 19.5 & 1.25 & 14.9 & 29.3 \\
\hline $2.08 \pm 0.26$ & $1.54 \pm 0.13$ & 0.49 & 43.96 & 11.7 & 6.26 & 11.4 & 26.3 \\
\hline $1.75 \pm 0.23$ & $1.44 \pm 0.12$ & 0.45 & 37.65 & 15.9 & 1.69 & 14.9 & 20.1 \\
\hline $1.76 \pm 0.30$ & $1.45 \pm 0.15$ & 0.46 & 43.12 & 10.5 & 7.87 & 12.1 & 23.1 \\
\hline $1.31 \pm 0.20$ & $1.43 \pm 0.18$ & 0.45 & 34.25 & 14.1 & 2.27 & 16.3 & 15.7 \\
\hline $1.44 \pm 0.19$ & $1.45 \pm 0.16$ & 0.46 & 42.06 & 9.59 & 8.86 & 13.4 & 19.8 \\
\hline
\end{tabular}

some inherent variability mainly related to the techniques used for its measurement and to a certain flow dependency. ${ }^{16}$

Therefore, it is necessary to perform in vitro studies to compare different mechanical prosthesis performances, as already stated for the aortic position. ${ }^{8,17}$ This concept has been put forward by other authors. Wagner and associates ${ }^{18}$ are aware that the in vivo measurement of gradients does not entirely represent the complex function of a valve, suggesting the performance of in vitro studies to complete what is already known from in vivo studies, and thus permitting the addition of other new parameters, such as TRV, VCV, VLV, and TEL, for the individual prostheses. Ruzicka and colleagues ${ }^{19}$ recently integrated in vivo results with those observed in vitro. However, the discussed in vitro and in vivo results were all obtained in the aortic position and were focused on aortic prosthesis-patient mismatch. Nevertheless, the in vivo mitral prosthesis-patient mismatch has been described by $\mathrm{Li}$ and colleagues ${ }^{5}$ and Pibarot and Dumesnil. ${ }^{14}$

The hypothetic differential hydraulic behavior between different prosthetic heart valves in the mitral position in children has not been demonstrated. Therefore, we maintain that it is absolutely essential to compare the hydrodynamic performances of different prostheses under defined and identical test conditions to obtain a meaningful comparison regardless of industry labeled size.

Our current study compared the hydrodynamic performances of 4 different mechanical prostheses fitting the atrioventricular annulus in children, regardless of label size, choosing the valves by comparing the prosthetic housing diameter and the predicted annulus diameter, calculated on the basis of body surface area. We observed that the label size of the Sorin Overline and SJM Regent prostheses correspond to the internal orifice diameter and external diameter, respectively. On the other hand, the same industry parameter does not correspond to any other measured dimensions for the Medtronic Advantage Supra and On-X prostheses.

Therefore, the comparison of hydrodynamics of different valve prostheses is difficult because of the lack of standardization in labeling by manufacturers. ${ }^{20}$ With the aim of allowing meaningful comparison that is relevant for clinical application, we designed this innovative study to analyze the hydrodynamics of these different bileaflet mechanical prostheses.

The SPD was used for this in vitro study. This device is not designed to give an accurate representation of the true

TABLE 5. Continued

\begin{tabular}{|c|c|c|c|c|c|c|c|}
\hline \multirow{2}{*}{$\begin{array}{l}\text { Valve leakage } \\
\text { volume }(\mathrm{mL})\end{array}$} & \multirow[b]{2}{*}{ EOA $\left(\mathrm{cm}^{2}\right)$} & \multirow{2}{*}{$\begin{array}{c}\text { Performance } \\
\text { index }\left(\mathrm{cm}^{2} / \mathrm{cm}^{2}\right)\end{array}$} & \multicolumn{2}{|c|}{ Total energy loss } & \multirow{2}{*}{$\begin{array}{c}\text { Forward flow energy } \\
\text { loss }(\mathbf{m J})\end{array}$} & \multirow{2}{*}{$\begin{array}{c}\text { Closing energy } \\
\text { loss }(\mathrm{J})\end{array}$} & \multirow{2}{*}{$\begin{array}{c}\text { Leakage energy } \\
\text { loss (mJ) }\end{array}$} \\
\hline & & & $(\mathbf{m J})$ & $(\%)$ & & & \\
\hline $1.49 \pm 0.24$ & $2.46 \pm 0.19$ & 0.85 & 34.87 & 16.2 & 0.15 & 17.2 & 17.8 \\
\hline $1.65 \pm 0.32$ & $2.46 \pm 0.15$ & 0.85 & 43.96 & 11.8 & 1.91 & 20.9 & 21.2 \\
\hline $1.52 \pm 0.22$ & $2.35 \pm 0.11$ & 0.81 & 37.12 & 16.7 & 0.06 & 18.9 & 18.3 \\
\hline $1.43 \pm 0.33$ & $2.27 \pm 0.10$ & 0.79 & 41.83 & 11.0 & 2.54 & 21.4 & 17.9 \\
\hline $1.07 \pm 0.13$ & $2.37 \pm 0.17$ & 0.82 & 35.11 & 15.1 & 0.26 & 22.1 & 12.8 \\
\hline $1.03 \pm 0.16$ & $2.00 \pm 0.18$ & 0.69 & 44.11 & 10.9 & 4.07 & 26.9 & 13.1 \\
\hline $0.85 \pm 0.13$ & $2.34 \pm 0.14$ & 0.81 & 37.33 & 15.5 & 0.53 & 26.7 & 10.1 \\
\hline $0.76 \pm 0.14$ & $1.93 \pm 0.19$ & 0.67 & 46.59 & 10.7 & 5.68 & 30.6 & 10.6 \\
\hline
\end{tabular}




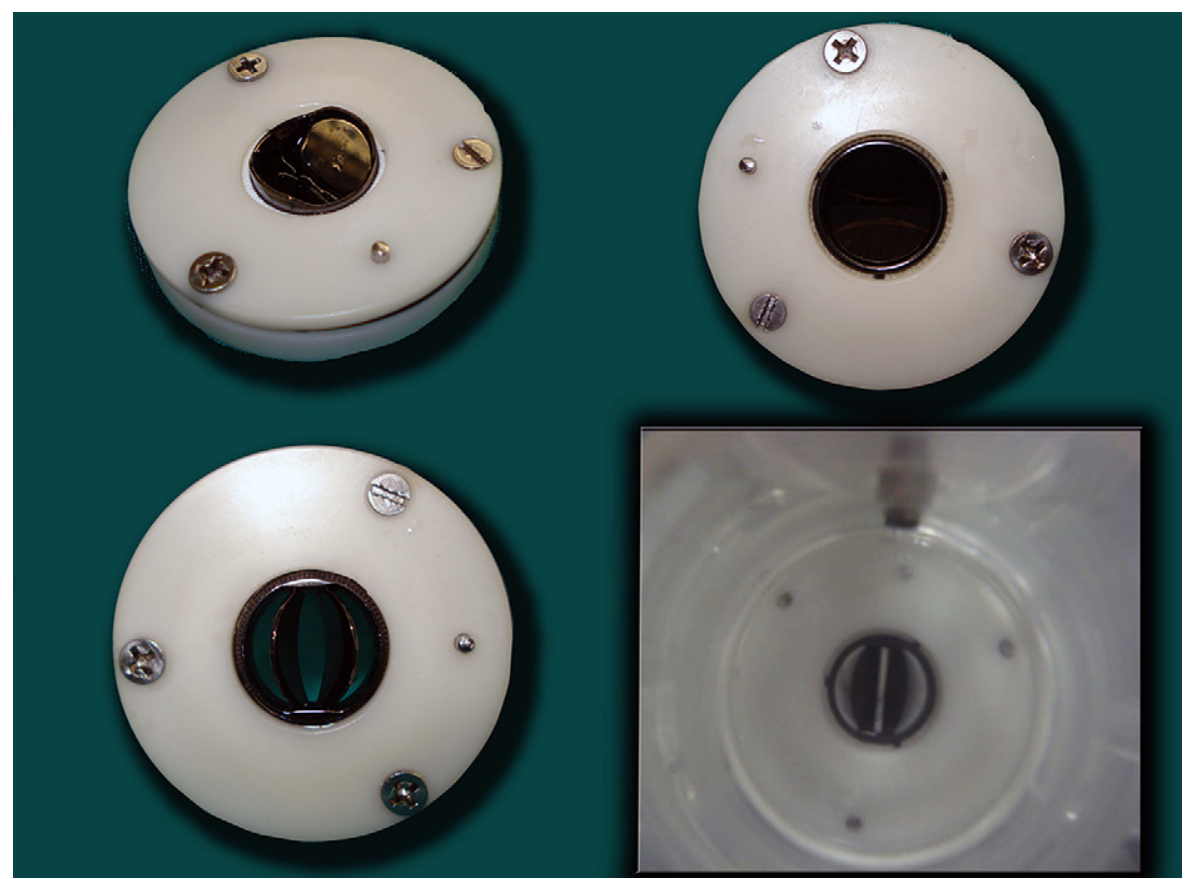

FIGURE 3. The valves inserted into the SPD holder $(21 \mathrm{~mm})$, which is composed of 2 O-rings. Each prosthesis was secured between these rings fitting perfectly, thus ensuring the lack of any perivalvular leakage, as shown: On-X (On-X Life Technologies, Inc, Austin, Tex); SJM Regent (St Jude Medical Inc, St Paul, Minn); and Sorin Overline (Sorin Biomedica, Saluggia, Italy). The Medtronic Advantage (Medtronic Inc, Minneapolis, Minn) is shown in the SPD during the tests.

anatomy, but it provides an extraordinary and unquestionable bench test for comparison of different prostheses exposed to the same conditions. ${ }^{8}$ However, we have to keep in mind that the transfer of the in vitro results to an in vivo situation is limited because the in vivo hemodynamic behavior of a valve may differ from in vitro idealized assumptions. ${ }^{8}$ For example, one of the major limitations of the current in vitro study is that the use of saline solution, strongly suggested by the SPD manufacturer, may lead to different results than those obtainable by using a fluid with a viscosity similar to blood. Therefore, we maintain that further studies comparing these in vitro results with in vivo echocardiographic findings are of extreme importance. In addition, the discussed data are the results of an independent research study, in which all of the authors disclaim any company relationship.

The mechanical aortic prosthesis may be inverted and placed in the mitral position (into the native annulus or in the supra-annular position), and used as a mitral valve substitute for pediatric patients undergoing MVR.

One option for maximizing the size of a mechanical prosthesis in small patients is to place the valve in a supraannular position, effectively within the left atrium (LA). Despite the potential benefits of a larger prosthesis in small children, supra-annular MVR has potential drawbacks, including reduction of LA volume and compliance, and aneurysm formation in the ventricularized segment of the LA between the prosthesis and the annulus. ${ }^{14}$ Consequently, it is mandatory to know the prostheses' functional characteristics according to different in vitro settings with the aim of giving the surgeon a quick idea of the appropriate valve to limit patient-prosthesis mismatch during somatic growth.

The current hydrodynamic evaluation model showed that all the tested valves behave differently in every test condition. In particular, the Sorin Overline valve possesses the lowest transvalvular gradients and the highest EOA, being significantly better at each CO. Although the Sorin Overline showed the best diastolic performance, it showed the highest regurgitant volumes because of its higher closure volumes. On the other hand, despite its highest transvalvular gradients, the Medtronic Advantage Supra showed particularly lower regurgitant and closing volumes, being significantly lower when compared with all the other tested valves. The SJM Regent and On-X valves showed intermediate results. For the TEL, the lowest regurgitant volumes observed with the Medtronic Advantage Supra valve led to surprising results. Despite its highest transvalvular gradients and lowest EOA, the Medtronic Advantage Supra valve showed the lowest TEL. On the other hand, despite the highest regurgitant volumes, the Sorin Overline showed an intermediate TEL and lower than that observed with the On- $\mathrm{X}$ valve because of its lowest transvalvular gradients. Native mitral valve incompetence, and thus mitral prosthesis incompetence, may play 

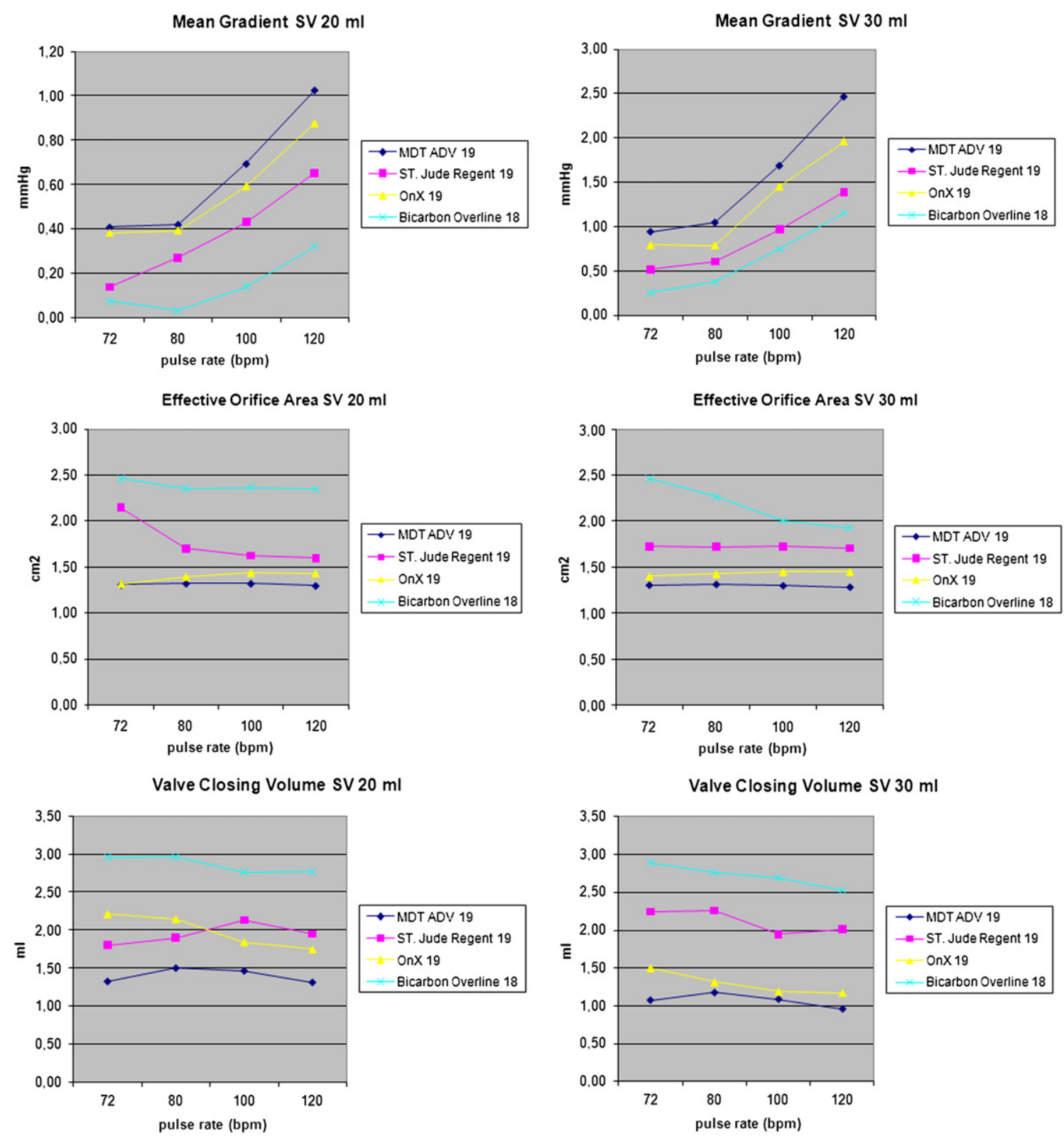

FIGURE 4. Mean pressure difference, EOA, and VCV of all valves tested.

an important role in left ventricle remodeling and LA pressure, modifying patient clinical outcome. ${ }^{14}$ Thus, as previously reported for the aortic position, ${ }^{17}$ for a meaningful and complete evaluation of prosthesis function it is necessary to consider both systolic and diastolic phases; otherwise, one risks a flawed analysis.

With the aim to limit these risks, we tested the prostheses in several different conditions, increasing the SV and PR, and thus increasing the $\mathrm{CO}$, simulating hypothetic somatic growth. Therefore, the different diastolic duration and mean diastolic flow rate, obtained at 20 and $30 \mathrm{~mL}$ of SV, led to a significant hydrodynamic modification for all the tested mechanical valves. The observed transprosthetic gradients were higher. Thus, because small flow modifications led to significant hydrodynamic differences, it is important to consider the results of in vitro tests for valve comparison, and not only the use of a fixed value of in vivo measured EOA, because in these settings the flow is an extremely variable parameter.

Furthermore, according to the specific design, only the SJM Regent, which has the pivots' housing toward the LA, could be placed in the supra-annular position, whereas all the others could be placed only within the atrioventricular annulus. 

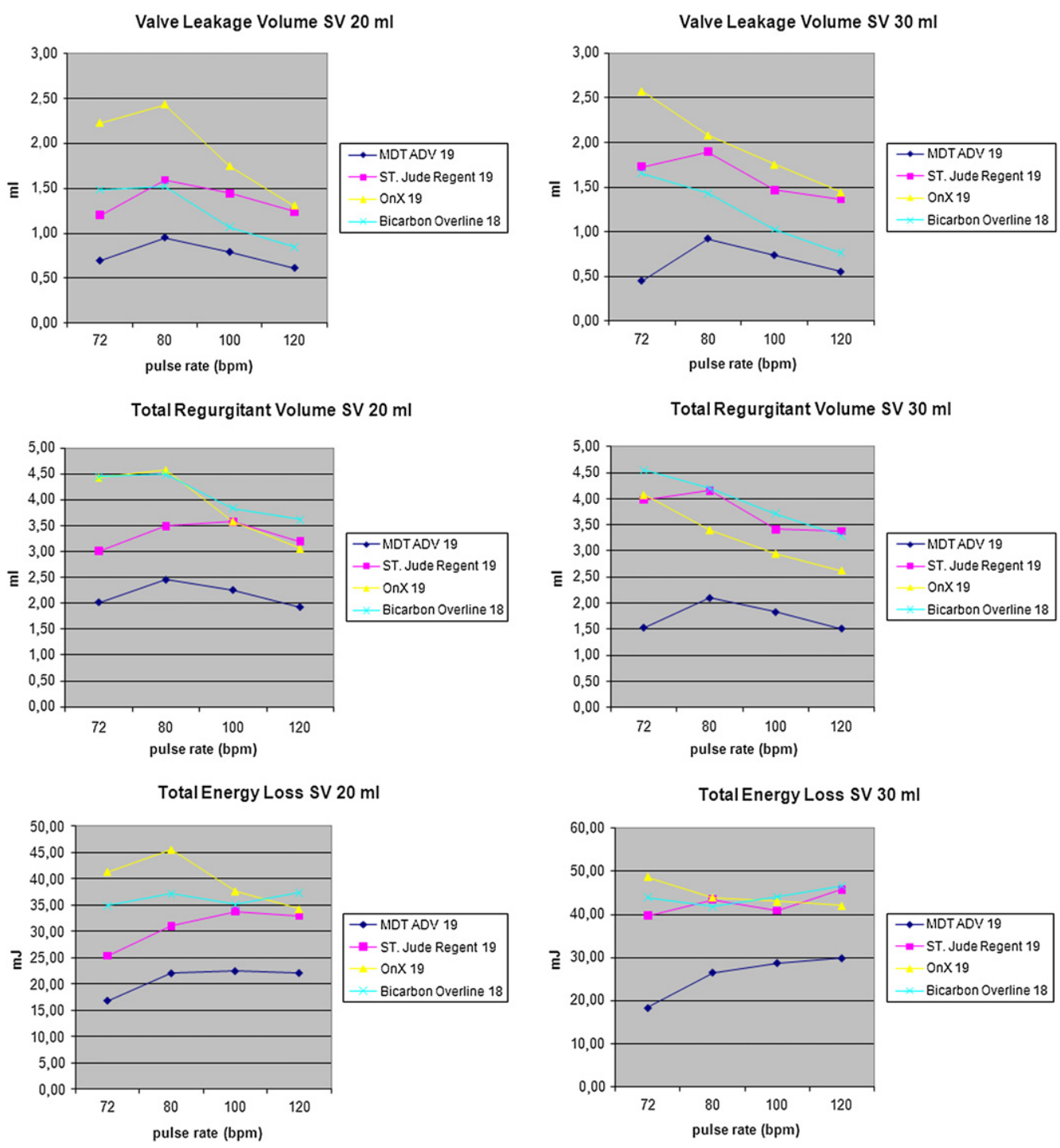

FIGURE 5. VLV, TRV, and TEL of all valves tested.

\section{CONCLUSIONS}

This hydrodynamic evaluation model allowed us to compare the efficiency of currently available valve prostheses suitable for atrioventricular replacement in children. Among these prostheses, the Sorin Overline exhibited the best diastolic performance, and the Medtronic Advantage Supra showed the lowest TEL.

\section{References}

1. Koch CG, Khandwala F, Estafanous FG, Loop FD, Blackstone EH. Impact of prosthesis-patient size on functional recovery after aortic valve replacement. Circulation. 2005;111:3221-9.

2. Rahimtoola SH. The problem of valve prosthesis-patient mismatch. Circulation. 1978;58:20-4.

3. Rao V, Jamieson WR, Ivanov J, Armstrong S, David TE. Prosthesis patient mismatch affects survival after aortic valve replacement. Circulation. 2000;102: III5-9.

4. Pibarot P, Dumesnil JG. Hemodynamic and clinical impact of prosthesis-patient mismatch in the aortic valve position and its prevention. J Am Coll Cardiol. 2000; $36: 1131-41$.
5. Li M, Dumesnil JG, Mathieu P, Pibarot P. Impact of valve prosthesis-patient mismatch on pulmonary arterial pressure after mitral valve replacement. J Am Coll Cardiol. 2005;45:1034-40.

6. Bottio T, Caprili L, Casarotto D, Gerosa G. Small aortic annulus: the hydrodynamic performances of 5 commercially available bileaflet mechanical valves. $J$ Thorac Cardiovasc Surg. 2004;128:457-62.

7. Gerosa G, Tarzia V, Rizzoli G, Bottio T. Small aortic annulus: the hydrodynamic performances of 5 commercially available tissue valves. J Thorac Cardiovasc Surg. 2006;131:1058-64

8. Bottio T, Tarzia V, Rizzoli G, Gerosa G. The changing spectrum of bioprostheses hydrodynamic performance: considerations on in vitro tests. Interact Cardiovasc Thorac Surg. 2008;7:750-4.

9. SPD Instructions Manual. Department of Medical Physics and Clinical Engineering. Sheffield, UK: Royal Hallamshire Hospital; 1997:1-39.

10. Walker DK, Brendzel AM, Scotten LN. The new St. Jude Medical Regent TM mechanical heart valve: laboratory measurements of hydrodynamic performance. J Heart Valve Dis. 1999;8:687-96.

11. Kadoba K, Jonas RA, Mayer JE, Castaneda AR. Mitral valve replacement in the first year of life. J Thorac Cardiovasc Surg. 1990;100:762-8.

12. Tierney ESS, Pigula FA, Berul CI, Lock JE, del Nido PJ, McElhinney DB. Mitral valve replacement in infants and children 5 years of age or younger: evolution in practice and outcome over three decades with a focus on supra-annular prosthesis implantation. J Thorac Cardiovasc Surg. 2008;136:954-61. 
13. Raghuveer G, Caldarone CA, Hills CB, Atkins DL, Belmont JM, Moller JH. Predictors of prosthesis survival, growth, and functional status following mechanical mitral valve replacement in children aged $<5$ years, a multi-institutional study. Circulation. 2003;108:174II-9II.

14. Pibarot P, Dumesnil JG. Prosthesis-patient mismatch in the mitral position: old concept, new evidences. J Thorac Cardiovasc Surg. 2007;133:1405-8.

15. Pibarot P, Dumesnil JG, Jobin J, Cartier P, Honos G, Durand LG. Hemodynamic and physical performance during maximal exercise in patients with an aortic bioprosthetic valve. J Am Coll Cardiol. 1999;34:1609-17.

16. Garcia D, Kadem L. What do you mean by aortic valve area: geometric orifice area, effective orifice area, or Gorlin area? J Heart Valve Dis. 2006;15: 601-8.
17. Bottio T, Tarzia V, Rizzoli G, Gerosa G. Valve prostheses evaluation: it is a complex scenario and not only a matter of gradient. Ann Thorac Surg. 2008;86:691-2.

18. Wagner IM, Eichinger WB, Bleiziffer S, Botzenhardt F, Gebauer I, Guenzinger R, et al. Influence of completely supra-annular placement of bioprostheses on exercise hemodynamics in patients with a small aortic annulus. $J$ Thorac Cardiovasc Surg. 2007;133:1234-41.

19. Ruzicka DJ, Hettich I, Hutter A, Bleiziffer S, Badiu CC, Bauernschmitt R, et al. The complete supraannular concept: in vivo hemodynamics of bovine and porcine aortic bioprostheses. Circulation. 2009;120:S139-45.

20. Chambers JB, Lionel OO, Narracott A, Lawford PM, Blauth CI. Nominal size in six bileaflet mechanical aortic valves: a comparison of orifice size and biologic equivalence. J Thorac Cardiovasc Surg. 2003;125:1388-93. 